\title{
Impacts of Design Exceptions on Highway Safety
}

\author{
Nikiforos Stamatiadis ${ }^{1 *}$ and Basil Psarianos ${ }^{2}$ \\ ${ }^{1}$ University of Kentucky \\ ${ }^{2}$ National Technical University \\ Inick.stamatiadis@uky.edu, ${ }^{2}$ bpsarian@mail.ntua.gr
}

\begin{abstract}
Design exceptions are used in roadway projects that require design elements that vary from typical designs. There have been concerns raised regarding the safety implications of the use of lower than typical design values. U.S. and International studies along with empirical evidence do not support this concern without practical design analysis and indepth consideration of factors associated with design parameter value selection. This study summarized past design exceptions in Kentucky to document their frequency and reason for their use and evaluate possible safety consequences from these exceptions. A site visit was made to a large number of the locations where the project was built with the requested design exception and available crash data were obtained at these locations. There was an average of 39 design exceptions per year for the 1993 to 2000 period. The majority of the projects involved a bridge replacement with the next most frequent being roadway widening reconstruction projects and construction of turning lanes. The most common design exception was for a design speed lower than the posted speed limit followed by a reduction in sight distance, curve radius, or shoulder width. The crash analysis showed that, with a very few exceptions, use of the design exception process did not have any negative effects on highway safety. The analysis showed that the design exception projects resulted in an improvement over the prior condition although some aspect of the design may not be typical.
\end{abstract}

Keywords: highway design, design exceptions, safety

\section{Introduction and Background}

The basic premise of a properly designed roadway is the consideration of mobility and safety issues while addressing its natural and human environmental aspects. To achieve such a balance, tradeoffs among these factors are needed and are routinely performed either explicitly or implicitly. The American Association of State Transportation Officials (AASHTO) publication titled "A Policy on Geometric Design of Highways and Streets" (commonly referred to as the Green Book) provides guidance to the designer by referencing a recommended range of values for critical dimensions for the design of new alignments and those undergoing major reconstruction [1]. Similar design approach can be also identified in other international design guidance like for example the 2008 edition of the German Guide for the Design of Freeways [2] and the recently published Guide for the Design of Rural Roads [3]. The same is also valid for the Greek Guide for the Design of Road Facilities [4]. These guidelines permit sufficient flexibility to encourage independent designs for specific situations and should not be considered as standards. Considering flexibility as part of the geometric aspects of roadways is not a new concept, since it has been stated clearly in the Green Book since its first edition as well as in European Guidelines. However, many designers have viewed the suggested values of the Green Book, the Greek Design Guide and other European Design guides as rigid standards instead of guidelines to be used in roadway design to achieve a reasonable degree of flexibility based on the roadway surroundings. Moreover, the Green Book for 
example indicates that the referenced guidelines provide a safe, comfortable, and aesthetically pleasing roadway.

An emphasis has been placed recently on the existing flexibility in design guidelines and the use of creative design in addressing the site-specific project needs has been encouraged. This philosophy was coined in the U.S. as Context Sensitive Solutions (CSS) and represents an approach where a balance is sought between safety and mobility needs within the community interests. Both the Federal Highway Administration (FHWA) and AASHTO recognize the flexibility that exists in the current design guidelines, while acknowledging that the current focus on providing high levels of mobility may conflict with some interests of the community. The use of multi-disciplinary teams and public involvement at the appropriate stages of the project are also aspects that promote CSS application. There is an increasing awareness of these CSS issues within the highway community through research and workshops. There is also a desire among the highway design community to improve and enhance established highway design practices and address the community interest elements. However, the current emphasis in CSS has created concern regarding the potential decrease of safety that may result from designing various features along roadways to accommodate community interests.

The Green Book supports flexibility to encourage independent designs versus rigid design standards. This approach allows the designer to introduce alternative design values for a specific element to better accommodate project needs. Design variances are commonly used to adjust almost all elements of geometric design. In 1997, FHWA published "Flexibility in Highway Design" to support designers in providing solutions to meet local design contexts [5]. AASHTO published "A Guide for Achieving Flexibility in Highway Design" in 2004 to support designers in attaining flexible designs [6]. While research has shown the safety implications of design exceptions does not have negative effects on highway safety, flexibility can create uncertainty for designers since there is limited data to quantify tradeoffs between design choices [6]. And while the Green Book supports safe, comfortable, and aesthetically pleasing roadways, it contains relatively little information regarding the safety and operational consequences of deviating from recommended values. The CSS approach encourages the designer to use creative design and move away from the "typical cross section" concept, where a standard template is used. There are often conflicting elements in a design and a designer is called upon to develop a solution that will balance several of these elements by designing a roadway non-conforming to the full values used up to that point. Table 1 shows for example the potential impacts from changes in selected design parameters [7]. It should be noted that increase in design speed does not always result in decreased safety if the roadway has been designed accordingly to address the higher speed. In instances where such deviations are implemented, design exceptions are applied to document and support the decision process. These documents should be viewed as an integral part of the design process, since there is a greater need today to balance the various roadway elements and deliver a product that is acceptable by the community and does not impact negatively the environment. 
Table 1. Potential Impacts from Changes in Selected Design Parameters [7]

\begin{tabular}{|c|c|c|}
\hline Feature & Change & Potential Impacts \\
\hline \multirow[t]{2}{*}{$\begin{array}{l}\text { Design } \\
\text { Speed }\end{array}$} & Increase & $\begin{array}{l}\text { - Shorter travel times (depends on LOS) } \\
\text { - Reduced opportunity to view features and } \\
\text { services adjacent to roadway } \\
\text { - Decrease in safety }\end{array}$ \\
\hline & Decrease & $\begin{array}{l}\text { - Increased opportunity to view features and } \\
\text { services adjacent to roadway } \\
\text { - Improved pedestrian/bicyclist environment } \\
\text { - Increase in safety }\end{array}$ \\
\hline \multirow[t]{2}{*}{$\begin{array}{l}\text { Lane } \\
\text { Width }\end{array}$} & Increase & $\begin{array}{l}\text { - Additional room for vehicles to maneuver } \\
\text { - Higher operating speeds } \\
\text { - Increased impervious surface } \\
\text { - Longer pedestrian crossing distances- } \\
\text { greater risk } \\
\text { - Can provide room for turning movements at } \\
\text { intersections } \\
\text { - Can provide room for additional lanes } \\
\text { - More room for bicyclists }\end{array}$ \\
\hline & Decrease & $\begin{array}{l}\text { - Reduced room for vehicles to maneuver } \\
\text { - Reduced capacity } \\
\text { - Reduced vehicle speeds } \\
\text { - Shorter pedestrian crossing distances } \\
\text { - Decrease in safety for pedestrians }\end{array}$ \\
\hline \multirow[t]{2}{*}{$\begin{array}{l}\text { Shoulder } \\
\text { Width }\end{array}$} & Increase & $\begin{array}{l}\text { - Increased space for errant and disabled vehicles } \\
\text { - Increased space for bicycles } \\
\text { - Increased impervious surface } \\
\text { - Increased impervious area to be mitigated } \\
\text { - Longer pedestrian crossing distances }\end{array}$ \\
\hline & Decrease & $\begin{array}{l}\text { - Reduced area for errant or disabled vehicles } \\
\text { - Reduced area for bicycles and pedestrians } \\
\text { - Reduced impervious area to be mitigated } \\
\text { - Shorter pedestrian crossing distances }\end{array}$ \\
\hline
\end{tabular}

The existing 13 controlling criteria were established by the FHWA when the 1984 Green Book was adopted as the standard for federal-aid projects (FHWA 1985). The Federal-Aid Policy Guide identifies the requirements for design exceptions and provides a list of 13 controlling criteria that require documentation to identify deviations from established minimum design criteria [8,9]. The list as presented in the Code of Federal Regulations (CFR) is applicable to roadways on the National Highway System (NHS). Most states have either used the list or modified it for their design exception process for roads off the NHS. The results from NCHRP Synthesis 316 indicated that many states (67 percent of responding agencies) use the same 13 controlling criteria as those prescribed in 23 CFR 625 in their design exception process [10].

A recent NCHRP study [11] examined the 13 criteria in order to determine current relationships between them and safety and operational considerations. The study also reviewed each criterion in a critical manner in order to determine its significance in current design efforts and whether it should be retained for future use. The study concluded that design speed should be treated differently than the other criteria and agencies should discourage or even prohibit its use as a design exception criterion. It is more appropriate to focus the design exception to specific design elements instead of using the design speed as a surrogate. The study concluded that shoulder and lane width should remain as criteria as well as horizontal curvature, superelevation, stopping sight 
distance, cross slope and grade. Bridge width, sag curve length, and horizontal offset did not show any safety implications and it is recommended that could be eliminated.

The design exception process allows for adjusting almost every aspect of the geometric design and may require both state and federal approval. A critical issue for the use of design exceptions has been their impact on safety. The notion of using values other than typical in various design elements has been viewed as a compromise to safety. Attempts to correlate various criteria to safety performance for design elements have been undertaken in the past. The Transportation Research Board Special Report 214 identified the safety effects for various design elements on Resurfacing, Restoration and Rehabilitation (3R) projects [12]. The analysis indicated that lane and shoulder width, shoulder type, roadsides and side slopes, bridge width, horizontal alignment, sight distance, intersections, pavement edge drop, and pavement surface condition have shown safety implications on two-lane rural roads. A quantitative estimate of safety effects resulting from altering their values was provided for all other design elements reviewed in Special Report 214. NCHRP Report 374 considered design aspects of horizontal and vertical alignments complemented by cross sectional elements [13]. The findings identified cross sectional elements (lane and shoulder width and cross slopes) that have quantifiable relationships with respect to safety and have produced preliminary Accident Reduction Factors.

Another typical case of the relationship between a design parameter and safety that in the past has initiated many conflicts and inconsistencies between design guidelines and empirical safety evidence represents the object height when calculating Stopping Sight Distances in the vertical alignment. A typical value of object height for an operating speed of $130 \mathrm{~km} / \mathrm{h}$ is equal to $0.45 \mathrm{~cm}$ according to the Greek guidelines for the design of roads [4]. This value was based on assumptions that aimed at addressing specific operating and travel conditions on a freeway. However, it is evident that early recognition of a plausible object on a freeway at $130 \mathrm{~km} / \mathrm{h}$ depends on many fuzzy parameters like its dimensions and form, the ambient light and its intensity, visual contrast of the object with the pavement etc. Various research projects have nevertheless shown that an impact of a vehicle on an obstacle in a freeway is statistically a very seldom case $[14,15]$. There are many indications lately that a proper and reality-based object on a freeway is a vehicle standing at the end of a vehicle queue and this should be considered as the design case in the future. This means practically that the height object should be raised to a value of 1.0 $\mathrm{m}$. Although this value can be adopted based on empirical evidence, a value of $0.5 \mathrm{~m}$ is nevertheless recommended on freeways generally to incorporate special conditions of vehicles moving in the fast lane of left-turn curves with median barriers higher than 0.80 $\mathrm{m}$, driver's orientation and fixed-eye behavior etc., [16]. This design value adoption does not mean that in specific cases an increase of the height object to $1.0 \mathrm{~m}$ would result in crash frequency and crash cost rate increase.

Stamatiadis [17] established the extent and implications of design exceptions in builtup areas. The report evaluated reasons for departures from guidelines in urban areas and identified procedures that could streamline the process to provide timely completion of the design exception process. Similar to Mason and Mahoney [10], the findings showed a varied design exception process among local transportation agencies. Both studies identified the need for consistent application of processes, as well as improved understanding of the safety performance, benefits, and tort liability implications associated with design exceptions.

There is a need to study the relationship between safety and design exceptions and determine whether there are any safety issues. A study was initiated in Kentucky that had as objectives to: a) summarize past design exceptions by documenting their frequency and reason for their use; b) evaluate the concept of design exception for future use; and c) determine any safety implications stemming from adopting design policies and practices related to design exceptions. 


\section{Methodology}

The Kentucky Transportation Cabinet maintains a file for each design exception. The amount of information related to any specific exception varies from only the Design Executive Summary form to fairly detailed background information. The design exception file for each case for the 1993 to 2000 period was obtained and reviewed. The data contained in the file were summarized to allow for classifying the design exception by various categories including types of project, exceptions requested, and the reasons for the exceptions requested.

An analysis of crash data was undertaken to determine the potential safety consequences of these design exceptions. Available crash data were obtained at these locations. Where possible, the dates of construction were obtained to accurately determine the before and after periods. Crash data were analyzed to determine the effect the design exception had on the crash history at the construction location. Some types of projects involved a complete reconstruction of the roadway that included more lanes. Such projects improved the safety of the roadway significantly and thus, it would be difficult to isolate the impacts of the design exception. To address this problem, two different procedures were used in the crash analysis. A before and after comparison was performed for cases where the roadway retained the number of lanes. For other roadways, a comparison of the location crash history to the statewide average for that type of road was performed. Consideration was given to development of crash rates by specific elements; however, this was not possible due to the limited data available for this research study. Site visits were completed to several locations to better understand the context and rationale for the design exception.

A desirable outcome from such a safety comparison is the determination of the relative safety impact of the values of specific geometric elements on safety. This implies that adequate data are available to establish such comparisons and that the impact of each element could be isolated. For example, this approach would allow for comparing lane widths and determining their relative impact on safety. However, the available data did not allow for such comparisons for various reasons. First, specific elements could not be isolated and examined alone since frequently more than one element was affected. Second, even for cases where only one element was modified, the number of crashes available was not adequate to statistically evaluate the safety consequences of varying the element's values. Third, there is significant variability among the projects examined such that even if an element was isolated, there were other variables (such as volumes, number of lanes, and functional class) that could also require attention and thus classify the data even further and reduce its strength in reaching statistically sound conclusions.

It should also be noted that Kentucky had retained sovereign immunity with an administrative claims procedure. Claims against the Transportation Cabinet are filed through the Board of Claims, which currently has maximum limits of $\$ 250,000$ for a single claim and $\$ 350,000$ for all claims related to one crash. There are offsets that can reduce the potential claim amount. Comparative negligence is the law in Kentucky, which allows a plaintiff to recover if any percent fault can be placed on the Cabinet. A key issue in cases related to roadway design is that design is a discretionary function, as opposed to a ministerial function, and requires engineering judgment to determine the most appropriate design considering all relevant factors

\section{Results}

\subsection{Number of Design Exceptions}

The annual numbers of design exceptions from 1993 through 2000 are summarized in Table 2. The categories provided in Table 2 are according to the general type of project provided in the project description of the Design Executive Summary form. There were 
319 design exceptions during the eight-year period considered. This represents an average of 40 per year with a range of from 24 in 1993 to 55 in 1998. The majority of the projects (57 percent) involved a bridge replacement. Second most common were roadway widening reconstruction projects (13 percent) followed by construction of a turning lane (9 percent).

Table 2. Type of Project by Year, 1993-2000

\begin{tabular}{lrrrrrrrrrr}
\hline & \multicolumn{8}{c}{ Year } & \multicolumn{1}{c}{} \\
\cline { 2 - 7 } \multicolumn{1}{c}{ Description } & 1993 & 1994 & 1995 & 1996 & 1997 & 1998 & 1999 & 2000 & Total \\
\hline Bridge Replacement & 14 & 26 & 27 & 40 & 27 & 29 & 9 & 14 & 186 \\
Widening/Reconstruction & 1 & 7 & 2 & 8 & 4 & 6 & 6 & 8 & 42 \\
Turning Lanes & 5 & 3 & 3 & 0 & 6 & 8 & 2 & 2 & 29 \\
Alignment & 1 & 0 & 1 & 1 & 1 & 2 & 5 & 0 & 11 \\
Relocation/New Construction & 0 & 0 & 1 & 0 & 1 & 3 & 5 & 1 & 11 \\
Intersection (general) & 1 & 2 & 1 & 1 & 0 & 1 & 2 & 2 & 10 \\
Pavement Rehabilitation & 0 & 3 & 3 & 1 & 0 & 2 & 0 & 1 & 10 \\
Raise Roadway Elevation & 1 & 0 & 0 & 0 & 0 & 3 & 1 & 0 & 5 \\
Sight Distance & 1 & 0 & 0 & 1 & 1 & 1 & 1 & 0 & 5 \\
Slide/Rock Fall & 0 & 1 & 1 & 0 & 0 & 0 & 1 & 2 & 5 \\
Spot Reconstruction & 0 & 1 & 0 & 0 & 1 & 0 & 0 & 1 & 3 \\
Ramp & 0 & 1 & 0 & 0 & 0 & 0 & 0 & 0 & 1 \\
Rest Area & 0 & 0 & 0 & 1 & 0 & 0 & 0 & 0 & 1 \\
& & & & & & & & & 319 \\
All & 24 & 44 & 39 & 53 & 41 & 55 & 32 & 31 & \\
& & & & & & & & & & \\
\end{tabular}

\subsection{Type of Design Exception Requested}

The types of design exception requested are summarized in Table 3. There was an average of 1.8 exceptions for each project. The most common design exception was to use a design speed lower than the posted speed limit (34 percent) with this exception commonly requested on bridge replacement projects. This type of exception was followed by a reduction in the minimum sight distance (12 percent), minimum curve radius (12 percent), or shoulder width (11 percent).

Table 3. Type of Design Exception Requested, 1993-2000

\begin{tabular}{|c|c|c|c|c|c|c|c|c|c|}
\hline \multirow[b]{2}{*}{ Exception } & \multicolumn{8}{|c|}{ Year } & \multirow[b]{2}{*}{ Total } \\
\hline & 1993 & 1994 & 1995 & 1996 & 1997 & 1998 & 1999 & 2000 & \\
\hline Design speed & 9 & 30 & 31 & 33 & 30 & 29 & 14 & 15 & 191 \\
\hline Minimum sight distance & 3 & 6 & s & 12 & 13 & 10 & 5 & 10 & 65 \\
\hline Minimum radius & 11 & 2 & 7 & 16 & 6 & 13 & 6 & 6 & 67 \\
\hline (Curvature) & & & & & & & & & \\
\hline Shoulder width & 7 & 12 & 3 & 5 & 5 & 16 & 9 & 6 & 63 \\
\hline Ditch width & 4 & 4 & 5 & 6 & 5 & 8 & 5 & 6 & 43 \\
\hline Pavement/lane width & 4 & 2 & & 15 & 7 & 8 & 1 & 4 & 42 \\
\hline Bridge width & 1 & 3 & ( & 14 & 7 & 6 & 1 & 3 & 35 \\
\hline
\end{tabular}




\begin{tabular}{lccccccccc} 
Number of lanes & 0 & 0 & 0 & 5 & 3 & 3 & 0 & 5 & 16 \\
Maximum grade & 1 & 2 & 2 & 2 & 0 & 4 & 3 & 1 & 15 \\
Superelevation & 0 & 1 & 0 & 1 & 0 & 9 & 1 & 0 & 12 \\
Acceleration lane & 0 & 1 & 2 & 1 & 0 & 0 & 0 & 0 & 4 \\
Clear zone/Border & 0 & 0 & 0 & 0 & 0 & 2 & 1 & 0 & 3 \\
Earth cut/fill slope & 1 & 0 & 0 & 0 & 1 & 0 & 0 & 0 & 2 \\
Bridge railing & 0 & 1 & 0 & 0 & 0 & 0 & 0 & 0 & 1 \\
Tie down & 0 & 0 & 0 & 0 & 0 & 1 & 0 & 0 & 1 \\
Access spacing & 0 & 0 & 0 & 0 & 0 & 0 & 0 & 1 & 1 \\
Guardrail end treatment & 0 & 0 & 0 & 0 & 0 & 0 & 0 & 1 & 1 \\
& & & & & & & & & \\
Total & 41 & 64 & 60 & 110 & 77 & 109 & 46 & 58 & 562 \\
\hline
\end{tabular}

The type of design exception was related to the most common types of project. For bridge replacement projects, the most frequent design exceptions were: design speed (39 percent), minimum sight distance (12 percent), minimum curve radius (11 percent), bridge width (8.9 percent) and pavement width (8.1 percent). For widening/reconstruction projects, the most frequent were: design speed (36 percent), minimum sight distance (16 percent), shoulder width (12 percent), minimum curve radius (10 percent) and ditch width ( 9 percent). The most common types of design exception for the addition of turning lanes were for shoulder width ( 35 percent) and ditch width ( 23 percent).

These data indicate that design speed is the most commonly requested type of exception for any project type. The need to use a lower speed than the posted speed limit points to the deficiency of the current approach for using design speed. Currently, design speed is selected based on functional class, terrain, and context of the roadway and is a decision that controls the geometric design elements. An alternative approach is the determination of the speed that is envisioned that drivers will drive on the roadway and using the expected operating speed as the design speed. The use of projected or observed operating speed as the design speed may avoid discrepancies between design and posted speeds, since roadways designed under this approach would achieve compatibility between posted and operating speeds. A basic requirement placed on roadway design is meeting the drivers= expectations by creating a consistent roadway design. Driver expectancy is formed by experience and has a significant influence on the driving task, since it can increase drivers $=$ readiness to complete a task. A consistent speed environment that conforms to driver expectations is desirable avoid abrupt changes in operating speeds and thus create a safe operating environment. The use of operating speeds as a means of designing this environment could alleviate the need to adjust design speeds and enhance design consistency.

\subsection{Reasons for Design Exception}

The reasons for the design exception were also examined to determine any possible trends (Table 4). There was an average of 1.7 reasons per design exception provided for justification. The most common reason referred to were the existing conditions on the road (66 percent). In many cases, this was further explained by a comment indicating that a design speed lower than the posted speed limit was requested to match existing roadway conditions. Another explanation of the existing conditions was problems with the existing horizontal and vertical alignment noting that it would not allow speeds higher than the requested design speed. This reason was followed by the right-of-way issue (33 percent) and project cost (25 percent). The usual comment made concerning right of way was that the exception would limit the amount of right of way needed for the project. The reason related to cost was that the cost to meet typical criteria would be excessive. These two 
reasons could be considered as one, since right of way costs are part of the project cost. Therefore, these reasons combined were very close to the first reason (58 percent) and may be indicative of the practical issues designers face when dealing with roadway projects. It should be noted here that the percentages were estimated based on the number of design exceptions and not on the reasons provided.

\section{Table 4. Reasons for Design Exception}

\begin{tabular}{lr}
\hline Reason & Number \\
\hline Existing conditions & 207 \\
Right-of-way issue & 103 \\
Cost & 78 \\
Length (scope) & 35 \\
Environmental & 27 \\
Adjacent property issue & 25 \\
Stop condition & 18 \\
Utility & 17 \\
Defer construction & 4 \\
Railroad issue & 2 \\
Lighting & 1 \\
Congestion & 1 \\
& \\
Total & 518 \\
\hline
\end{tabular}

The crash history of the project was noted in 21 projects (6.7 percent). The actual crash history was specified in only a very few instances. The reference was usually a comment that there had been several crashes at the project site in the past several years with no specific data provided. There was a general reference to safety concerns noted for 12 other projects. However, a review of the crash history at these locations did not typically find any problem prior to construction of the project.

Historic or environmental features were also noted in 17 projects including a variety of features. The most common reference noted impacts to a stream or wetland with other features including a historic register property and a stone masonry wall.

\subsection{Crash Analysis}

It was determined that site visits would provide additional information regarding the safety consequences of the design exception and allow for better understanding of the conditions for the exception. The locations were selected to provide a range of types of projects, design exceptions and adequate statewide coverage. Projects where crash history was a reason for the design exception as well as cases with historical or environmental concerns were given higher priority. Finally, projects completed within the time frame that would allow for collecting crash data and available before construction data were sought. Following this process, 86 sites were identified and site visits were conducted. When possible, the crash history at the locations was summarized using the available data. As noted earlier, the objective was to determine possible safety consequences from the design exceptions. In order to conduct a before and after type of analysis, the start and end dates of the construction are desirable and the construction must have occurred during a time period for which before and after crash data were available. Since crash data could typically be obtained for the years of 1995 through 2000, the construction period had to be within these years to allow a before and after comparison. Moreover, sufficient time should have passed after the construction to allow for significant crash history to develop. 
An alternative to the before and after analysis for the older projects, where before data is not readily available or where the exact date of construction is not known, would be to calculate the crash rate at the location after the project and compare that rate with statewide crash rates for similar types of roads. This approach would allow for determining whether the design exception had any effect as compared to similar roads, which are presumably constructed without any exceptions.

The crash analysis was conducted for 65 of the 86 sites due to available crash history. Locations off the state maintained system are not included, since crash data are not available at those locations. In many cases, the construction date was recent and this did not allow for adequate after data to be collected and thus, would not allow for any detailed before and after type of analysis. The crash history was obtained at some locations where the construction has not been completed and compared to statewide averages to determine if there had been a crash problem.

The analysis showed that, for all but 6 of the case study sites, constructing roadways with design elements representing design levels other than typically used did not affect the safety level of the project. This resulted in the construction of projects with crash rates lower than either: a) average rates for the type of location where the project occurred or b) the crash rate at the site before the construction occurred. Therefore, it could be concluded that constructing roadways with "other than typical" design values for some geometric elements does not affect negatively the safety of the projects. It should be stressed that, even though different than typical values were utilized, they were always within the acceptable values suggested by the Green Book.

As mentioned earlier, there were 21 projects ( 6.7 percent) where a direct reference to a prior crash problem was noted in the background information. Moreover, there were another 12 locations (3.8 percent) with a general reference to safety concerns. It could then be assumed that the introduction of design elements with lower values may have an adverse effect on the safety level of these sites. However, the improvements made to these roadways had a positive impact on the safety level at these sites, since the construction improved the overall characteristics of the site. This is also true for most of the sites, since when comparing the existing geometric conditions before construction, the improvement projects resulted in improved roadway geometrics at all sites.

\section{Conclusions}

For several state agencies, the undocumented effects of design exceptions on safety have acted as a barrier in their wider use. The concern is that the use of other than typical values will result in lower safety levels and it may also increase liability. This study aimed to first summarize past design exceptions by documenting their frequency and reason for their use and then determine the possible safety implications due to using such design policies and practices in Kentucky.

The most common design exception involved a reduced design speed at a bridge replacement project. The typical reason for the exception was that the design conformed to the existing conditions on the roadway adjacent to the project and thus, there is no need to construct a bridge that would conflict with the context of the roadway. Roadway widening and shoulder addition were the next types of projects most frequently requested. For these projects the use of a reduced design speed was most frequently noted. These data indicate that there may be a need to revise the method by which design speeds are determined and used in roadway design. Moreover, these data may be indicative of the need for using a different type of speed that would reflect the operating conditions of the roadway rather than an abstract design speed. This was also noted in the Mason and Mahoney state policy review [10]. NCHRP Report 783 also recommends the treatment of the design speed differently than other criteria and recommends discouraging or even prohibiting its use as a design exception [11] 
Another issue of bridge replacement projects is the need for wider lanes on the bridge, since current design guidance could often require a wider roadway width across the bridge. In most cases, approaches to older bridges have a narrower roadway width than the proposed width. In these cases, the design exception involves the need for narrower lane and/or shoulder widths to accommodate the approach dimensions. As noted in Table 4 , the most common reason for requesting a design exception is that of "Existing Conditions". This typically refers to having a project that current design guidance requires it to be designed with elements "larger" than the exiting conditions and thus creating an anomaly within the section. For example, several projects dealt with the replacement of a curve where current design guidance may require a wider lane to be used than the existing lane width. In such cases, in order to maintain a uniform cross section, the lane width was exempted from becoming wider while the curve issue was addressed. The crash analysis shows that use of the design exception process has not resulted in segments with higher crash rates than those observed before. The projects constructed with the design exceptions resulted in an improvement over the prior condition although some aspect of the design may not be typical. The reasons for the design exceptions have been well documented, and there is no evidence that construction of projects with a design exception had an adverse effect on highway safety, based on the findings here. It should also be noted that safety was improved from the existing design but no assessment was possible for determining the incremental change in the safety of the design exception versus the original design.

This analysis demonstrates the lack of any safety consequences from the design exceptions in Kentucky and it recommends that the current design exception process could continue. Of interest here is the fact that most sites showed a lower crash rate after the construction. However, it should be pointed out that this could be partially attributed to the fact that the constructed site has improved significantly from the previous design. It would be desirable to continue monitoring these sites and determine their safety level in the future by comparing them with other similar sites throughout the state.

The findings of the study also point toward future research to further evaluate the safety consequences of design exceptions. One issue to be considered is that of safety consequences for specific crash types. Even though this aspect was not examined here due to lack of available data, it could be possible that changes in design values for a design element could affect specific crash types more than others. Severity of crashes could be another factor to be examined, since trading fatalities for property damage crashes may be an easier choice to make. It should also be noted that designing a roadway according to "standards or the highest design values" does not necessary make it a safe roadway. Another possible future research effort could be the comparison of similar roadways constructed with and without design exceptions. This will allow for the development of control and test sites and will provide some answers regarding the relative safety between typical and "other than typical" design values. The study indicates that the concerns regarding potential safety issues from the use of design exceptions are not supported. It should be noted that there are always tradeoffs between applications of flexible design and safety; however, the key to this dilemma is to reach that appropriate balance where the designer is comfortable and the intervening factors demanding flexibility have been addressed. The design exception is a useful tool that designers should be encouraged to use, since at minimum it provides a reasonable documentation process for design choices made for a roadway project. The basic idea of documentation is central to the decision process and could limit potential liability concerns. This tool allows designers to complete a design that is sensitive to the context of the roadway without compromising safety. 


\section{References}

[1] American Association of State Highway Transportation Officials, A Policy in Geometric Design of Highways and Streets, Washington, D.C. (2011).

[2] Forschungsgesellschaft für das Straßen- und Verkehrswesen, Richtlinien für die Anlage von Autobahnen (RAA), Köln, (2008).

[3] Forschungsgesellschaft für das Straßen- und Verkehrswesen, Richtlinien für die Anlage von Landstraßen, (RAL), Köln, (2012).

[4] OMOE-X, Guidelines for the Design of Highways Facilities, Part Alignment Design, Athens, (2001).

[5] Federal Highway Administration. Flexibility in Highway Design, FHWA-PD-97-062, Washington, D.C. (1997).

[6] American Association of State Highway Transportation Officials, A Guide for Achieving Flexibility in Highway Design. Washington, D.C. (2004).

[7] J. Milton and A. St. Martin, eds. Understanding Flexibility in Transportation Design-Washington, WSDOT, Olympia, (2005).

[8] Federal Highway Administration, Implementation of New Design Criteria for Federal-Aid Projects, Memorandum April 15, 1985, Washington, D.C. (1985).

[9] Federal Highway Administration Policy CFR 625.1, Washington, D.C. (2005). http://www.fhwa.dot.gov/design/0625sup.cfm accessed 4/2/15

[10] J. Mason and K. Mahoney, "Design Exception Practices", NCHRP Synthesis Report 316, Transportation Research Board, Washington, D.C. (2003).

[11] D. Harwood, "Evaluation of the 13 Controlling Criteria for Geometric Design", NCHRP Report 783, Transportation Research Board, Washington, D.C., (2014).

[12] Transportation Research Board, Designing Safer Roads; Practices for Resurfacing, Restoration, and Rehabilitation, Special Report 214, Washington, D.C., (1987).

[13] H. McGee, W. Hughes and K. Daily, "Effect of Highway Standards on Safety", NCHRP Report 374, Transportation Research Board, Washington, D.C., (1995).

[14] Ch. Lippold, Weiterentwicklung ausgewählter Entwurfsgrundlagen für Landstraßen Dissertation Darmstadt, (1996).

[15] W. Krüger, S. Weiser, Sichtweiten in Linkskurven zweibahniger Straßen; Forschung Straßenbau und Straßenverkehrstechnik, Heft 886, Bonn Bad Godesberg, (2004).

[16] Ch. Lippold, T. Lehmann, W. Ressel and A. Benner, Entwurfshinweise zum sicheren sechsstreifigen Ausbau von Autobahnen, Schlussbericht FE 02.269/2006, Bundesanstalt für Straßenwesen, Dresden, (2010).

[17] N. Stamatiadis, "Design Flexibility Considerations for Built Urban Environments", Research Results Digest 337, NCHRP, Transportation Research Board, Washington, D.C., (2009). 
International Journal of Transportation

Vol.5, No.1 (2017) 